c. Albertisi MaIndR. ( $\left.{ }^{1}\right)$. - Les exemplaires que j'ai reçus du $\mathrm{D}^{\mathrm{r}}$ Gestro proviennent, comme ceux que m'avait déjà donnés M. R. Oberthür, du Fly River.

Les neuf espèces suivantes sont actuellement les seules décrites de Nouvelle-Guinée, et elles paraissent particulières à la région :

Colpodes Sloanei MaIndr., - C. violaceus Chadd., - C. habilis Sloane, - C. Bennigseni Sloane, - C. papuensis Sloane, - C. annulicornis Maindr., - C. Albertisi MAIndr., - C. Laglaizei MaIndr., C. Novae Guineae MaIndR.

A l'exception des $C$. habilis, Sloanei et violaceus, qui se rapprochent des formes indochinoises, indomalaises et indiennes, les autres Colpodes néoguinéens rentrent dans la catégorie des formes océaniennes, d'une manière générale, s'entend.

\title{
Description d'un nouveau genre et d'une nouvelle espèce de Lampyrides [CoL.]
}

\author{
par E, Olivier.
}

J'ai reçu, il y a quelque temps, dans un envoi de l'Amérique du Sud, un Lampyride extrêmement remarquable par la conformation toute spéciale de ses antennes. M. le $\mathrm{D}^{\mathrm{r}}$ Gestro ayant bien voulu me communiquer dernièrement une intéressante série d'insectes de ce groupe appartenant au Musée de Gênes, j’y ai trouvé un individu semblable.

Ces deux Lampyrides diffèrent complètement de toutes les espèces déjà connues, et nécessitent la création d'un nouveau genre.

Petalacmis, gen. nov. - Tête complètement recouverte par le prothorax; dernier article des palpes maxillaires épaissi, trapu, sécuriforme. Antennes simples, longues, composées de 9 articles : le $\mathbb{1}^{\mathrm{er}}$ plus long que les deux suivants réunis, élargi au sommet; le $2^{\mathrm{e}}$ court, en cône renversé; les $3^{\mathrm{e}}$ à $8^{\mathrm{e}}$ très courts et très serrés; le $9^{\mathrm{e}}$ formé par une lamelle allongée, plate, arrondie au sommet, à bords légèrement flexueux, presque deux fois aussi longue que les 8 articles précédents. Prothorax à bord postérieur droit, à angles nullement saillants. Pattes grêles, dernier article des tarses allongé, à peine plus long que les lobes du précédent; crochets simples. Abdomen fortement

(1) Bull. Soc. ent. Fr. [1906], p. 24. 
lobé latéralement, pygidium trilobé. - $\checkmark$. Appareil lumineux occupant les trois derniers segments du ventre. - $\uparrow$. Inconnue.

Ce genre est bien caractérisé par la forme bizarre des antennes dont je donne un dessin fait par mon ami Robert Du BuYsson. Il ne comprend jusqu'à présent qu'une seule espèce, trouvée dans l'Amèrique du Sud, de taille peu considérable et qui offre le faciès d'un petit Photinus.

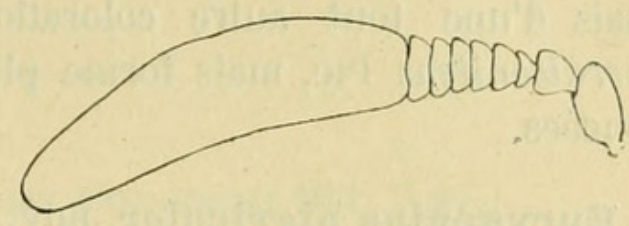

Petalacmis praeclarus, sp. nov. - Elongatus, subparallelus, brunneus, pubescens; capite nigro; ore et palpis piceis; antennis piceis, prothorace longioribus, novem articulatis, ultimo articulo alteris fere duplo longiore; prothorace elongato, subquadrato, lateribus rectis, antice rotundato, basi recte truncato, angulis haud prominulis, punctato, flavido, macula discoidali brunnea; scutello parvo, triangulari, brunneo; elytris elongatis, subparallelis, rugosis, costulatis, brunneis, sutura et margine externo tenuiter dilutioribus; pedibus piceis; abdominis segmentorum angulis valde retro productis; pygidio trilobato; duobus penultimis ventris segmentis cereis, lucidis. - ․ Ignota. - Long. : 8 mill.

Bolivie (Mus. de Gênes); Brésil (ma collection).

\section{Trois Hétéromères nouveaux de l'Afrique orientale [CoL.]}

par Maurice Pic.

Gistela abyssinica, nov. sp. - Satis elongatus, antice posticeque attenuatus, subconvexus, nitidus, coeruleo-viridescens, palpis, antennis tarsisque nigris, femoribus tibiisque luteis.

Assez allongé, atténué aux deux extrémités, subconvexe, brillant, d'un bleu verdâtre avec les pattes, sauf les tarses qui sont noirs, jaunes, les antennes et palpes noirs. Tête assez longue; antennes grêles; prothorax plus long que large, assez rétréci antérieurement, presque droit postérieurement, faiblement sinué à la base, avec une faible impression de chaque côté de celle-ci, à ponctuation assez fine et dense; élytres à peine plus larges que le prothorax, subparallèles, acuminés au sommet, à stries ponctuées assez profondes avec les 


\section{$2 \mathrm{BHL}$ Biodiversity Heritage Library}

1908. "Description d'un nouveau genre et d'une nouvelle espece de Lampyrides." Bulletin de la Société entomologique de France 1908, 186-187. https://doi.org/10.5962/bhl.part.5610.

View This Item Online: https://www.biodiversitylibrary.org/item/37020

DOI: https://doi.org/10.5962/bhl.part.5610

Permalink: https://www.biodiversitylibrary.org/partpdf/5610

\section{Holding Institution}

Smithsonian Libraries

\section{Sponsored by}

Smithsonian

\section{Copyright \& Reuse}

Copyright Status: NOT_IN_COPYRIGHT

This document was created from content at the Biodiversity Heritage Library, the world's largest open access digital library for biodiversity literature and archives. Visit BHL at https://www.biodiversitylibrary.org. 